\title{
A historiografia do nazismo nos últimos quinze anos: um ol- har sobre a produção em língua inglesa
}

\author{
The Nazism's historiography in recent years: a look at the English \\ speaking world production
}

João Fábio Bertonha*

EVANS, Richard. The Third Reich in History and Memory. London: Abacus, 2016, $483 \mathrm{p}$

Richard Evans é um dos mais importantes historiadores do nazismo. Professor da Universidade de Cambridge, ele escreveu obras seminais sobre a história alemã e, especialmente, sobre o Terceiro Reich, todas baseadas em solida pesquisa empírica e arquivística em vários países e em amplo domínio da monumental e sempre crescente bibliografia histórica sobre o tema.

No livro em questão, ele é menos o historiador que revela algo novo a partir do resgate ou da reinterpretação de documentos e mais aquele que utiliza o conhecimento acumulado em décadas de leitura para avaliar o que se escreve sobre o tema. Em vinte e oito pequenos ensaios, ele apresenta um panorama geral do que vem sendo produzido, em língua inglesa, nos últimos quinze anos, grosso modo o século XXI.

*Professor de História (Graduação e Pós-Graduação) na Universidade Estadual de Maringál Paraná. Doutor em História pela Universidade Estadual de Campinas.

Email: fabiobertonha@hotmail.com 
Uma originalidade do livro é que todos esses ensaios foram escritos no formato de resenha. Resenhas, como se sabe, podem ser meramente descritivas, apresentando ao leitor a obra resenhada e o convidando a fazer a sua leitura ou analíticas, as quais utilizam o objeto da resenha como ponto de partida para reflexões mais amplas sobre o tema em discussão. Regra geral (mas não absoluta) é que as primeiras são normalmente escritas por iniciantes, os quais procuram enriquecer seu currículo com publicações, mas sem se arriscar a uma crítica real da obra estudada. Já as segundas demandam um conhecimento mais amplo sobre o tema e a disposição para o debate, pelo que são normalmente escritas por veteranos no assunto.

Richard Evans, como já mencionado, só poderia ser incluído na segunda categoria e é isso que faz das suas reflexões sobre o trabalho dos outros algo tão instrutivo e enriquecedor. Ele, além disso, é um historiador de alto rigor metodológico, exigindo continuamente, dos autores que resenha, rigor na interpretação das fontes, no domínio da literatura secundaria, na análise crítica de memorias e depoimentos, etc. Isso significa que as suas considerações não são baseadas em subjetividades ou em posturas de ordem ideológica, mas em rigorosos padrões de pesquisa acadêmica, os quais só podem ser atingidos após anos de estudo e aperfeiçoamento.

Os temas abordados no livro são inúmeros, indo desde o carro do povo, o Volkswagen, a arte e as utopias urbanas na época da guerra até a vida cultural de Berlim nos anos 1920, a biografia de Walter Rathenau ou as empresas de armamentos Krupp. Aqui e ali, as repetições são inevitáveis, já que vários dos assuntos abordados, inevitavelmente, se intercruzam e se conectam. O conjunto forma, não obstante, um sólido panorama da produção historiográfica em língua inglesa sobre o nazismo nos últimos quinze anos.

A sua exigência de rigor acadêmico e de análise cuidadosa das fontes e da bibliografia o permite anular "armadilhas" políticas e historiográficas, como quando relativiza a comparação entre os massacres nazistas e soviéticos na Europa oriental ou o papel dos diplomatas alemães no Terceiro Reich e no Holocausto. Especialmente interessantes são os momentos em que ele utiliza a sua régua analítica na direção de argumentos ou temas de interesse para a mídia ou a cultura popular, como as doenças e a vida sexual de Hitler.

No primeiro caso, ele analisa vários dos mitos que procuraram explicar o seu antissemitismo ou o seu fanatismo, como uma suposta ascendência judaica, sua contaminação por sífilis por uma mulher judaica, sua relação incestuosa com a mãe ou uma hipnose mal resolvida. Sua conclusão é que as evidências nada comprovam e, pelo contrário, indicam que tudo isso não passa de rumores ou boatos sem fundamento, recuperados pela mídia para alavancar as vendas de seus produtos ou para aliviar a consciência culpada dos alemães. Do mesmo modo, sua homossexualidade ou suas inclinações sado masoquistas teriam sido construções baseadas em frágeis indícios, sendo o mais provável que ele fosse 
um homem heterossexual relativamente comum.

A ideia de que ele tivesse sido um viciado em drogas ou remédios também é testada e a conclusão geral é a de que sua saúde não era particularmente boa, mas, ainda assim, dentro dos padrões esperados para um homem da sua idade e posição na sua época. Seus problemas de saúde também não teriam sido ampliados por um suposto tratamento errôneo pelo Dr. Theo Morrell, que teria seguido práticas médicas que pertenciam ao profissionalmente aceitável na época.

Ele também comenta a suposta insanidade de Hitler e, com base nas recentes pesquisas sobre o tema, a refuta. Hitler tinha uma maneira particular de ver o mundo, baseada numa racionalidade própria que tinha sua base de partida em mitos e mitologias. Ele não era, contudo, insano e todas as tentativas de explicar o fenômeno Hitler por supostas anomalias em sua biografia - doença mental ou física, vício em drogas, tendências homossexuais não resolvidas, etc. - não passariam de esforços para que a sociedade alemã e europeia pudesse lidar com seu passado e esquecer que suas crenças eram compartilhadas por milhões e que seus atos foram, de alguma forma, apoiados e sustentados por parcelas substanciais da população alemã e do continente.

A busca pela racionalidade do nazismo é algo que permeia boa parte dos livros resenhados, numa indicação dos rumos historiográficos atuais. Por décadas, os historiadores tentaram compreender as motivações nazistas dentro de perspectivas racionais, iluministas. Quais seriam as reais motivações por trás do Holocausto, da perseguição implacável aos eslavos ou aos homossexuais? Não seria possível que um povo sofisticado, como o alemão, tivesse acreditado nos mitos conspiratórios antissemitas, nos sonhos imperiais nazistas no Leste Europeu ou na mitologia do corpo racial alemão a ser purificado. Deveria haver motivações outras, escondidas, e elas deveriam estar - especialmente se a base teórica do historiador fosse marxista - no econômico, no social.

$\mathrm{Na}$ verdade, na minha interpretação, o que havia era a dificuldade em conciliar duas versões da palavra "ideologia", ou seja, conjunto de ideias de uma pessoa ou grupo e visão invertida do mundo real. No ponto de vista de muitos historiadores, o nazismo tinha bases ideológicas tão absurdas - de um ponto de vista racional - que sua ideologia só podia ser uma tentativa de esconder os interesses de fundo, econômicos, de classe, etc. Ou, no máximo, uma desculpa para questões de momento, como a necessidade de suprir a Alemanha de alimentos ou aumentar a vigilância sobre os povos dominados.

É verdade que motivações imediatas estavam presentes e vários dos ensaios do livro mencionam isso. Um exemplo foi a crise de abastecimento de alimentos e o recrudescer da luta guerrilheira no novo Império alemão a partir, mais ou menos, de 1942, as quais aceleraram políticas já existentes de eliminação de "bocas inúteis" eslavas e judias. As contingências de momento, contudo, apenas reforçavam os preconceitos e percepções mentais, não os 
criavam.

As fontes reais da política nazista estavam efetivamente mais no campo das mitologias e dos mitos do que no racionalismo puro e simples. Em vários dos ensaios, Evans questiona a real importância da experiência colonial alemã anterior, especialmente na Namíbia, para a imaginação imperial nazista e indica como essa imaginação tinha inspiração em fontes muito mais longínquas, como a britânica ou a americana. Hitler imaginava o Leste europeu como um novo Far West ou uma nova Índia, onde colonos alemães iriam subjugar, pela simples superioridade racial e pela força bruta, as massas de nativos e, com o tempo, substituí-los. Uma visão mítica que não levava em conta, por exemplo, o esforço de acomodação, compromisso e colaboração que os ingleses, por exemplo, usavam para manter seu Império na Índia e na África com relativamente pouco esforço.

Do mesmo modo, o tema do Holocausto acaba por adquirir novo significado dentro da historiografia sobre o tema. Debatendo com vários livros e autores, Evans discute uma questão central: foi o Holocausto uma experiência histórica única ou apenas um capítulo dentro de uma história humana repleta de massacres, genocídios e violência coletiva?

Para responder isso, sua primeira tarefa é comparar os massacres nazistas na Europa do Leste com os perpetrados pelos soviéticos, especialmente na parte oriental da Polônia, por eles ocupada de 1939 a 1941. É evidente que Stalin também tinha ambições de remodelar a região em favor de uma utopia, o socialismo, assim como Hitler tinha no tocante ao nazismo. É também evidente que ambos os ditadores agiram com brutalidade extrema nesse sentido.

Evans recorda, contudo, como a violência soviética era dirigida não contra um povo ou etnia em particular, mas contra grupos e classes que pareciam ser um obstáculo real a seus planos. A deportação, a fome e os assassinatos tinham um objetivo instrumental de eliminar resistências, reais ou imaginárias, enquanto o nazismo pensava no extermínio como um projeto em si, de limpeza racial. Ele indica, igualmente, outra diferença substancial: o objetivo soviético era o de incorporar as novas regiões ao sistema e não o de excluir e, por fim, exterminar um povo em particular, como fez o nazismo.

Nesse ponto, eu acrescentaria que Hitler e Stalin seguiram, dentro de um modelo de ambições totalitárias, as tradições de "esquerda" e "direita", como indicadas por Bobbio, no sentido de igualdade e desigualdade. Stalin concedeu, aos povos recentemente dominados, o direito de serem iguais aos demais soviéticos, na esperança de dias melhores e na repressão implacável. Já Hitler, ao lidar com os conquistados, estabeleceu imediatamente a hierarquia racial e começou a eliminar os considerados indignos até mesmo de viver.

Em seguida, ainda nesse esforço de contextualização do Holocausto, Evans recorda como as ambições genocidas dos nazistas não se limitavam aos judeus. No caso dos eslavos, sua ambição era claramente a de exterminar 
algumas dezenas de milhões de poloneses, ucranianos e outros povos do Leste para "abrir espaço" para a expansão ariana. Já durante a guerra, esse projeto foi sendo levado a cabo, sendo cabível recordar aqui, apenas como exemplo, o extermínio pela fome de 3 milhões de soldados soviéticos prisioneiros de guerra e as maciças deportações de poloneses do território anexado pela Alemanha e pertencente à antiga Polônia. Os massacres dos ciganos também poderiam ser recordados como indício de que os judeus não foram as únicas vítimas da violência nazista.

Evans ressalta, contudo, em vários dos ensaios, como o extermínio dos judeus não pode ser visto como apenas um capítulo a mais dentro de um projeto mais amplo de reorganização racial da Europa. Os eslavos da Polônia ou da Ucrânia, por exemplo, eram um obstáculo físico a ser removido de forma a "abrir espaço" para os colonizadores germânicos. Seriam explorados impiedosamente enquanto fossem úteis e depois eliminados. Os nazistas não pensavam, contudo, na destruição de todos os eslavos no mundo e nem consideravam isso algo necessário. Os eslavos, enquanto raça inferior, não eram uma ameaça existencial aos arianos - a não ser quando liderados por judeus, como os bolcheviques, o que dava contornos precisos, aliás, ao mito "bolchevique-judeu" - e sua eliminação completa não era necessária, a não ser em regiões específicas.

Também os ciganos eram um problema de "higiene", de eliminação de um elemento racial inferior, mas os nazistas não os viam como uma ameaça que tornasse a sua destruição uma tarefa urgente e necessária, tanto que muitos sobreviveram. Os nazistas, também nesse caso, simplesmente exerciam um poder colonial, reorganizando o espaço e eliminando os que poderiam atrapalhar a construção do Império.

Os judeus entravam em outra categoria, de Weltfeind, inimigo mundial e eterno a raça ariana. Sua destruição era um dos objetivos fundamentais, senão o mais importante, da guerra iniciada em 1939. Derrotar os Aliados no campo de batalha era fundamental, mas essa vitória seria incompleta sem a destruição física do povo judeu, o qual, na mitologia nazista, era a fonte de todo o mal na Terra. Isso explica a obsessão nazista em procurar e exterminar judeus em todos os lugares e o desvio de fundamentais recursos econômicos e militares para isso.

A novidade do genocídio judeu não estaria, portanto, no método empregado para o assassinato (ainda que o uso do gás e os métodos industriais fossem um diferencial), mas no fato de se basear, fundamentalmente, em mitos e mitologias e por não ter limites delimitados pelo tempo ou pelo espaço. Os judeus seriam exterminados onde quer que estivessem (e, caso as condições o permitissem, isso teria acontecido também no Oriente Médio ou nas Américas) porque, do ponto de vista nazista, essa era a luta de vida e morte entre duas concepções de mundo, entre duas forças titânicas e eternas que disputavam a 
humanidade desde sempre, luz e escuridão.

Mesmo outros antissemitismos não compartilhavam essa abrangência, essa visão cosmológica da questão judaica. Como ele menciona em vários momentos, os regimes da Croácia e da Romênia agiram contra os judeus (assim como contra outras minorias), assassinando-os ou expulsando-os com vista à purificação racial de seus países. No entanto, eles viam os judeus como um problema nacional e, no máximo, regional. A sobrevivência do povo judaico em outros países ou regiões não era motivo de preocupação, o que forma uma diferença marcante com relação ao modelo nazista.

Nesse aspecto, aliás, estaria também o elemento central que diferenciaria o genocídio judeu do armênio ou dos hereros na Namíbia, por exemplo. Em ambos os casos, turcos e alemães procuraram remover um obstáculo aos seus sonhos imperiais ou de expansão e homogeneidade racial, mas não imaginavam armênios ou africanos como ameaças transcendentais à sua existência. Nesse caso, estariam mais próximos da relação nazista com os eslavos e não com os judeus.

Evans conclui que o Holocausto, enquanto fenômeno histórico, pode e deve ser comparado com outros genocídios e que o ocorrido com os judeus durante a Segunda Guerra Mundial foi, efetivamente, um capítulo dentro de livros muito maiores, como a história dos massacres e limpezas étnicas na História ou a tentativa de reorganização racial da Europa pelo nazismo. Foi, contudo, um capítulo muito especial, a ser visto e compreendido dentro dessa ótica.

Outro ponto forte do livro é quando ele discute a questão da coerção e do consenso dentro da nova historiografia relacionada ao nazismo e, especialmente, as oscilações entre um e outro polo.

Com efeito, os estudos sobre o nazismo e os fascismos (e, na verdade, sobre as ditaduras em geral) enfatizavam, num primeiro momento, a questão da dominação do Estado sobre a sua população. Os historiadores se concentravam no sistema repressivo, na propaganda e em temas semelhantes, enfatizando a questão da coerção. Depois, num momento posterior, a ênfase passou para o outro lado. Não apenas a capacidade do sistema repressivo e da propaganda em controlar totalmente as pessoas passou a ser questionado, como passou a se ressaltar o seu consenso e a sua adesão ao regime.

Em vários dos ensaios, Evans comenta sobre o contexto político que levou a essa mudança de foco por parte dos historiadores, fazendo com que a maioria dos alemães que viveram de 1933 a 1945 parasse de ser considerado "vítimas", como no período anterior, para receberem outras classificações, como "perpetradores" ou "culpados".

Ele não contesta as novas pesquisas, as quais indicam os limites do aparato repressor e propagandístico do regime e que ele não teria se mantido sem algum tipo de adesão, ativa ou passiva, do grosso da população. Evans, 
no entanto, é especialmente crítico sobre duas das bases que sustentam essa nova visão.

Em primeiro lugar, ele questiona a suposta legalidade da chegada do nazismo ao poder, a qual indicaria a adesão alemã ao projeto nazista. A violência e a intimidação teriam estado presentes em todo o processo eleitoral que deu maioria parlamentar ao nazismo e mesmo essa maioria era tão tímida que foi necessário o apoio dos partidos conservadores para a sua consolidação. No período crítico de fevereiro a junho de 1933, por sua vez, elas teriam sido as chaves para demolir resistências - especialmente na esquerda, mas também entre liberais e conservadores - e consolidar o poder de Hitler.

Em segundo, ele indica como é reducionista imaginar que o sistema repressivo nazista se restringia à Gestapo e aos campos de concentração. $\mathrm{O}$ efetivo da Gestapo era efetivamente muito pequeno para controlar a Alemanha e poucos alemães, proporcionalmente, foram enviados a campos de concentração. O centro da repressão, contudo, era outro: o sistema legal e coercitivo que já existia. Depois do período crítico de consolidação no poder, a maior parte da repressão e da vigilância vinha das cortes tradicionais e era conduzida pelas forças policiais do Estado.

Outros agentes, como os inspetores de quarteirão ou a juventude hitlerista, amplificavam e se somavam às tradicionais para tornar o sistema ainda mais radicado no território. Dessa forma, considerar que o povo alemão vivia sob a dominação de um poder repressivo demiúrgico seria errado, mas imaginar o seu oposto também seria um excesso.

Em resumo, ele compartilha as críticas feitas por, por exemplo, Nicola Tranfaglia e outros historiadores do fascismo italiano frente à hipótese de um "consenso fascista" na Itália dos anos 1930: só é possível falar de "consenso" ou de "adesão" quando ele é dado livremente e quando existem alternativas. Em caso de ameaças físicas ou simbólicas, seria mais real falar de "resignação" do que "consenso", ainda que diferentes gradações de apoio possam ser identificadas conforme o tempo, o grupo social, etc.

Richard Evans ressalta, assim, algo tão básico que nem precisaria ser recordado: o nazismo era um sistema de ideias e práticas no qual a violência, o terror e a coerção eram centrais. Quaisquer julgamentos de valor moral sobre as decisões tomadas pelas pessoas que viviam em tal situação só podem ser tomados levando-se em consideração esse fato, ainda que isso não os torne impossíveis.

Para finalizar, a leitura do presente livro com certeza não significa que seja possível se esquivar da tarefa de ler diretamente, na fonte, as muitas dezenas de títulos que ele comenta e discute. Ler os comentários de um historiador do porte de Evans sobre os mesmos, contudo, é um excelente referencial para apoiar essas leituras maiores e é recomendável aos interessados na temática.

Resenha recebida em novembro de 2016. Aceito em janeiro de 2016. 